\title{
The Relationship between Efficiency and Level of Satisfaction on CPD among Teachers
}

\author{
Mohd Jasmy Abd Rahman, Low Weng Sheng, Md. Yusoff Daud, Nur Kamariah Ensimau \\ The National University of Malaysia, Bangi, Malaysia \\ Email: mjas@ukm.edu.my,nurncmau@gmail.com
}

How to cite this paper: Rahman, M. J. A., Sheng, L. W., Daud, Md. Y., \& Ensimau, N. K. (2019). The Relationship between Efficiency and Level of Satisfaction on CPD among Teachers. Creative Education, 10, 3223-3234.

https://doi.org/10.4236/ce.2019.1012246

Received: October 21, 2019

Accepted: November 27, 2019

Published: November 30, 2019

Copyright $\odot 2019$ by author(s) and Scientific Research Publishing Inc. This work is licensed under the Creative Commons Attribution International License (CC BY 4.0).

http://creativecommons.org/licenses/by/4.0/

\begin{abstract}
The aim of this study was to identify the level of efficiency among teachers in Bachang Zone and their satisfaction towards online CPD. The survey has been conducted among 181 respondents in Bachang Zone, Malacca in order to identify the relation between teachers level of knowledge on ICT and their satisfaction based on gender and ages. The study showed that teacher who has more knowledge in ICT has a highly satisfaction. However, the comparative analysis found that teachers' efficiency on ICT was varied by gender, not by age. Meanwhile, the level of CPD satisfaction was significant by gender and ages. Therefore, this study suggested that various educational organizations should provide teachers with the assistance in ICT and improve the training website system to be more user-friendly and the similar conducted in rural areas also mostly welcomed.
\end{abstract}

\section{Keywords}

Technology and Information Skills, Service Satisfaction Training, Online, Teachers

\section{Introduction}

Information and Communication Technology skills were the goal of education because computer skills contribute to the success of learning (Kuhlemeier \& Hemker (2007). Therefore, there was an important role to ensure the satisfaction of teachers in online training. It is also in line with the 7th Shift in PPPM 2013-2025 (Ministry of Education Malaysia, 2012), which utilizes ICT to enhance the quality of learning in Malaysia. This may indicate that the ICT is a key element in 21st century learning (Mohd Jasmy \& Norazani, (2017) as future education is digital. According to Goh et al. (2010), raising the level of employee skills at the basic level or providing continuous retraining is crucial to achieving 
the goals of an organization. This is because human resources are the most valuable asset for an organization. Therefore, continous professionalism training programs are one of the important tools for expanding the human resource potential and thus enhancing the quality and quality of staff within the organization. In line with the 21st century, the use of advanced information and communication technologies has made it easier for teachers to access online in-service training regardless of time and place such as through the Open Learning Website, OER, EPSA, eP-MABLS, the site education of the state of Malacca (Malacca Department of Education, (2017)) and so on. EPSA and eP-MABLS learning are considered as training and credit hours will be included in SPLKPM. This means that teachers can manage their own training online and learn new knowledge and skills on their own initiative anywhere and anytime. Teachers who have not completed the 7-day training can also take this initiative to meet the current year's requirements. Numerous studies have also shown that continuous training can improve teacher work performance and is important in transforming a lagging practice. In short, our education system has changed dramatically in terms of widespread use of ICT. Studies have found that a teacher's ICT skills level can influence the effectiveness of a program that requires the use of computers and IT (Sheiladevi \& Rahman, (2016). High ICT skills play an important role in influencing teachers' job satisfaction in facing IT-related challenges (Mohd Jasmy \& Md. Yusoff (2015). Therefore, teachers need to ensure that they enhanced their skills on ICT in order to raise their level of work satisfaction.

\section{Problem Statement}

The CPD is an effort to improve the quality of continuing education services for a teacher. However, the Education Development Plan 2013-2025 (2012) report showed that teachers only managed to deliver $50 \%$ of their teaching effectively. This proves that the CPD is less successful and that the teachers still cannot bring about the changes they have made through the CPD even after the CPD started in 2005. This is very important because teachers are agents of change in school. If a change or practice set in the KPM level is not implemented properly, it will affect the quality of student teaching and learning process. Fullan and Stiegelbauer (1991) also concluded that one of the reasons for in-service training failure was the "one-time only" workshop and that the selected topics were not involved as program participants. This is because teachers only attend one course for a specific purpose. Therefore they unable to master $100 \%$ of the course content and this will affect the school because nothing would change after all. In other words, teachers and speakers just wasted their time in pursuing a practice. The changes on CPD through online learning such as EPSA and eP-MABLS (JPM, 2017) are a new initiative in the world of teacher education to address existing weaknesses. It was also created to meet the needs of teachers in order to motivate them to enhance their professionalism. Due to recent changes and the lack of studies on the relationship between ICT skills and online CPD 
p0satisfaction in the context of Malaysia, I conducted this study to justify the relationship between ICT skills and online CPD satisfaction so that teachers can enhance their professionalism through CPD over online based on their needs. The training received will certainly enhance the quality of education as it will motivate teachers to continue to learn and improved their accountability as educators in schools.

\section{Literature Review}

In the world, there are teachers who are good at ICT and some who are not. Wong et al. (2002) showed that there are two extreme groups of there, the first one were those with high efficiency in productivity tools and those who are inefficient. Ahmad Hambali (2015) shown that there is no significant difference between the level of proficiency in the ICT of teachers based on gender, but there are significant differences based on the age and teaching experience of a teacher. In addition, Juan et al. (2016) believe that while teachers have improved their knowledge in phonemic awareness, systematic phonetic instruction, fluency, vocabulary and strategies for understanding the components after the completion of an online web-based training session, teachers' beliefs also show a positive impact by both two pre-service and in-service teachers. This is in line with the findings of Goh (2012) which found that teachers' level of knowledge about in-service training is high but satisfaction level is moderate. In addition, the findings also show that the correlation between knowledge level and teacher satisfaction level is strongly positive relationship. The study also found that independent variables such as gender and teacher education did not influence the level of knowledge and the level of satisfaction of teachers with in-service training conducted in schools. Nonetheless, race and teaching experience show the difference between level of knowledge and level of satisfaction. Sugunah (2014) found that there is a moderate positive relationship between teachers' ICT skills and knowledge management in schools. He also suggested that the CPD in schools should focus on learning the basics of basic ICT skills. However, without effective implementation, the objective of the course could not be achieved. Therefore, a well-planned strategy was really needed. Areej \& Abdulrahman (2011) presented the proposal VLE implementation framework in higher education institutions and one of the issue have been address was the training designs programs to increase awareness of the use of VLE. In line with the above, Sharifah \& Kamarul (2011) found that teachers who were ready to implement teach-

ing using the ICT approach have a strong relation between work and behavior. Awang et al. (2011) stated that teachers do not have the time to hold discussion sessions to share ideas to improve their teaching methods. Therefore, it can be said that the implementation of knowledge management through ICT can enhance the knowledge and skills of teachers at any time, but it involves high costs such as the purchase of ICT equipment and provision of facilities. Kler (2014) states that the use of ICT in knowledge management can help a teacher reduce 
the information gap. This means that teachers can improve their knowledge through online in-service training. They will feel satisfied when they are able to improve their skills to achieve an educational objective. This will only happen when teachers have the ICT skills to access this information. Zawiyah \& Zuhri, (2014) found that the use of Facebook Group is appropriate for the purpose of sharing knowledge rather than forging relationships between teachers and students. In addition, Aesaert et al. (2015) states that the lack of competency of teachers in the ICT will affect the achievement of students' performance in school and may not develop their own knowledge.

\section{Methodology}

Survey and correlation studies using quantitative approaches were used as the design of this study. The study was conducted in Bachang zone, Melaka which involved 15 schools. Based on the Krejcie sampling method, R. V and Morgan D. W (1970) in the book Azizi et al. (2016), a total of 181 teachers were randomly selected to be sampled in this study. Table 1 shows the demographics of gender and age of the respondents

In this a quantitative study, an instrument is a questionnaire used only to collect the data of the variables from the study sample. The questionnaire consisted of three sections, Part A, 2 items collecting demographic information, Part B, 10 items collecting teachers 'ICT skills level information and Part C, 25 items collecting teachers' online CPD satisfaction data. This instrument has been certified by a lecturer in the field at UKM. The pilot results showed that the alpha and Part C items were alpha values of 0.93 and 0.97 , respectively. The survey questionnaire was distributed to 181 teachers in Bachang zone, Central Malacca, Malacca in the form of Google Form.

Data was collected from respondents using SPSS software version 20 by means of descriptive and inference analysis such as t-test, ANOVA test and correlation test. The interpretation scales for the mean data scores are as shown in Table 2. Adapted from Izani \& Yahya (2014). While the range scores for the relationship strengths of the variables in this studied can refer to Table 3.

\section{Research Findings}

\subsection{Level of Teacher Efficiency on ICT in Bachang Zone, Malacca}

Part B items have been distributed and the questionnaire was analyzed descriptively. The table showed the level of ICT among teachers in Bachang Zone. Referring to Table 4, it showed teacher level of efficiency on ICT in the Bachang zone, Malacca was very high with mean $=4.37$; s.p. $=0.547$.

Analysis showed that teachers in Bachang zone schools, Malacca dominated the content knowledge Category $(\mathrm{min}=4.44$; s.p. $=0.483)$ compared to the assignment category $(\min =4.31$; s.p. $=0.659)$. However, both dimensions are very high and the mean differences were only 0.13 . 
Table 1. Respondent demographic.

\begin{tabular}{ccc}
\hline Demography & Frequency $(\mathbf{n})$ & Percentage (\%) \\
\hline Gender & 32 & 17.7 \\
Male & 149 & 82.3 \\
Female & 181 & 100.0 \\
Total & & \\
\hline Ages & 35 & 19.3 \\
$21-30$ years old & 76 & 42.0 \\
$31-40$ years old & 49 & 27.1 \\
$41-50$ years old & 21 & 11.6 \\
$51-60$ years old & 181 & 100.0 \\
Total & & \\
\hline
\end{tabular}

Table 2. Interpretation of min score.

\begin{tabular}{cc}
\hline Score Min & Min \\
\hline $1.00-1.89$ & Extremely Low \\
$1.90-2.69$ & Low \\
$2.70-3.49$ & Moderate \\
$3.50-4.29$ & High \\
$4.30-5.00$ & Extremely High \\
\hline
\end{tabular}

Table 3. Range of relationship of variables.

\begin{tabular}{cc}
\hline Score Min & Interpretation Score Min \\
\hline 0.00 & Not relate \\
$<0.19$ & Extremely Weak \\
$0.20-0.39$ & Weak \\
$0.40-0.69$ & Moderate \\
$0.70-0.89$ & High \\
$>0.90$ & Very High \\
\hline
\end{tabular}

Table 4. Level of teacher efficiency on ICT.

\begin{tabular}{cccc}
\hline Dimension & Score Min & Standard Deviation & Level \\
\hline Content Knowledge Category & 4.44 & 0.483 & Very High \\
Assignment/Task Category & 4.31 & 0.659 & Very High \\
Level of Efficiency on ICT & 4.37 & 0.547 & Very High \\
\hline
\end{tabular}

\subsection{Teachers Level of Satisfaction towards Training Online Services}

Part $\mathrm{C}$ items were evaluated on teachers satisfaction and Table 5 had shown that teachers level of satisfaction on which was high (mean $=3.77$; s.p. $=$ 0.490). 
Table 5. Teachers level of satisfaction towards training online services.

\begin{tabular}{lccc}
\hline \multicolumn{1}{c}{ Dimension } & Score Min & Standard Deviation & Level \\
\hline Satisfaction toward management of CDP online & 3.75 & 0.611 & High \\
Satisfaction toward operate of CPD online & 3.81 & 0.536 & High \\
Satisfaction on the benefits of CPD online & 3.76 & 0.484 & High \\
Teachers level of satisfaction on CPD online & 3.77 & 0.490 & High \\
\hline
\end{tabular}

The analyze shown that teachers in Bachang zone were most satisfied with the satisfaction towards management on CPD online score was $(\min =3.81 ; \mathrm{sp}=$ 0.536), followed by the satisfaction the benefits gained after attended CPD online score $(\min =3.76 ; \mathrm{sp}=0.484)$ the lowest was the satisfaction with online CPD online management $(\mathrm{min}=3.75 ; \mathrm{sp}=0.611)$. All of these dimensions scores were high and the mean difference between the highest and lowest dimensions was only 0.06 .

\subsection{Contribution of ICT Efficiency towards Level of Satisfaction on CPD Online among Teachers in Bachang Zone, Malacca}

The level of ICT Efficiency and the online level of CPD satisfaction analyzed were performed in a statistical inference correlation test. A total of 181 questionnaires were studied. Based on Table 6, it shows the correlation between the level of ICT efficiency and the level of online CPD satisfaction of teachers in Bachang zone, Malacca. The results analyzed using the Pearson correlation show that the correlation score was 0.576 . It shows the correlation relationship at a simple positive stage. The results show that the value of sig. (2 tailed) displaying alpha values less than 0.05 . Thus, it can be concluded that there was a significant relationship between the level of ICT efficiency and the level of CPD online satisfaction of teachers in schools. Therefore, Hol was rejected. This means that the level of ICT Efficiency contributes to teacher satisfaction towards online $\mathrm{CPD}$. Based on the findings of this study, one of the factors contributing to the teachers' satisfaction in the online LDP implementation is due to their high level of ICT skills.

\subsection{Teachers Efficiency on ICT Based on Genders and Ages}

Table 7 showed the T-test analyze where there was a signification on teachers efficiency on ICT based on gender $(\mathrm{t}(4.00)=0.000 ; p<0.05$ (95\% CI $=0.156$ until 0.465 . Therefore, Ho2 was rejected. It showed that level on efficiency were different between men and women whereby the men teachers were more skills than women.

Table 8 indicated the one way ANOVA analysis that shows there were no significant value between ages and teachers efficiency, $\mathrm{F}(3,177)=0.543 ; p>0.05$. Therefore, Ho3 was accepted.

\subsection{Level of Satisfaction on CPD Based on Gender}

Based on Table 9, $\mathrm{t}$-test showed that there was no relation between level on 
Table 6. The correlation between level of management leadership and teachers satisfaction.

\begin{tabular}{cccc}
\hline & & $\begin{array}{c}\text { Level of management } \\
\text { leadership }\end{array}$ & $\begin{array}{c}\text { Level of teachers } \\
\text { satisfaction }\end{array}$ \\
\hline Level of Efficiency CPD & Correlation Pearson & 1 & $0.576^{* *}$ \\
& Sig. (2-tailed) & 181 & 0.000 \\
Level of Satisfaction & Correlation Pearson & $0.576^{* *}$ & 181 \\
towards CPD Online & Sig. (2-tailed) & 0.000 & 1 \\
& $\mathrm{~N}$ & 181 & 181 \\
\hline
\end{tabular}

Table 7. T-test on teacher level of efficiency based on gender.

\begin{tabular}{cccccc}
\hline Variables & N & Min & Standard Deviation & T & $\begin{array}{c}\text { Significant } \\
\text { Value }\end{array}$ \\
\hline Men & 32 & 4.63 & 0.352 & 4.00 & $0.000^{* *}$ \\
Women & 149 & 4.32 & 0.566 & & \\
\hline
\end{tabular}

Table 8. One way Anova Test based on gender.

\begin{tabular}{cccccc}
\hline \multicolumn{7}{c}{ ANOVA } \\
\hline \multicolumn{7}{c}{ Teachers Efficiency on ICT } \\
\hline Total Chi square & df & Min Chi Square & F Value & Sig. \\
\hline In Group & 0.646 & 3 & 0.215 & 0.717 & 0.543 \\
Between Group & 53.176 & 177 & 0.300 & & \\
Total & 53.822 & 180 & & & \\
\hline
\end{tabular}

Table 9. T-test based between level of satisfaction and gender.

\begin{tabular}{cccccc}
\hline Variable & N & Min & Standard Deviation & T & Significant Values \\
\hline Men & 32 & 3.95 & 0.655 & & 0.087 \\
Women & 149 & 3.74 & 0.441 & 1.78 & \\
\hline
\end{tabular}

satisfaction and $\mathrm{t}(1.78)=0.087 ; p>0.05$ (95\% CI $=-0.033$ until 0.459). Therefore, $\mathrm{Ho} 4$ was rejected because the level of satisfaction between men and women were same.

Table 10 showed the result of One Way ANOVA whereby there were no significant between levels of satisfaction and $\mathrm{F}(3,177)=0.691 ; p>0.05$. Therefore, Ho5 was rejected.

\section{Discussion}

\subsection{Teacher in Bachang Zone, Malacca Were High Level of Efficiency in ICT}

The findings of this study contradict the results of the study of Wong et al. (2002), Ahmad Hambali (2015) and Kleiman (2000) that teachers' ICT efficiency 
Table 10. One way ANOVA test based on gender.

\begin{tabular}{ccccccc}
\hline \multicolumn{5}{c}{ ANOVA } \\
\hline \multicolumn{5}{c}{ Level of Satisfaction } \\
\hline Total Chi Square & df & Min Chi Square & F Values & Sig. \\
\hline In group & 0.355 & 3 & 0.118 & 0.488 & 0.691 \\
Between group & 42.942 & 177 & 0.243 & & \\
Total & 43.297 & 180 & & & \\
\hline
\end{tabular}

was at a high and medium level and teachers were less competent in using technology especially computers. Based on study conducted by Luo \& Bu, (2015), the high level of efficiency in ICT help to increase the productivity of emerging economies. As such, the use of ICT has been incorporated into the education system in our country. Many applications and administrative work have used ICTs whereby the teachers need to be skilled in using them to cope with their work routine as a teacher. The findings of this study also indicate that teachers were more proficient in content categories. Teachers were less skilled in preparing document using computer because it involved more formulas and not frequently used. Therefore, MOE or JPN tend to prepare the form or templates and teachers just key in the data. Teachers also less skilled in drawing. This is because teachers do not use these techniques and skills frequently plus most of graphics can be easily downloaded directly from the internet. However, more teachers prefer to use power point slides where graphics can be edited directly within the application.

\subsection{Teacher Level of Satisfaction towards CPD Online}

The results show that the level of online LDP satisfaction of teachers was high. The findings of this study show an increasing compared to the results of Goh's (2012) study which found that teacher satisfaction was moderate. This was supported by the study of Kokoc et al. (2011) that the time and place constraints can be overcome through online CPD because it can provide quality training. The finding regarding dimension found that based on management of CPD online the result was most satisfied which was inline with Goh's (2012) study. Teachers were very satisfied with the content of training in online services because it is relevant to them. This finding was line with the results of Sharifah and Kamarul (2011) which stated that material suitability was at a high level of $77.5 \%$. All of these courses offer the work of a teacher and they can choose whatever they like or need. Furthermore, satisfaction with the benefits gained after following the CPD online also shows a high degree. However, it was found that teachers do not have the knowledge to identify students' problems specifically after training in online services. This was because it requires training in the form of workshops where teachers need to be guided hands-on to learn these skills. Online training provides information whereby the facilitator does not provide direct guidance to teachers when taking online courses. This was line with the study of Kokoc et al. 
(2011) state that issues of accommodation and transportation can also be solved through online training. However, the most dissatisfying item is the duration of training in online services. Teachers do not know how much time should be spent preparing a course offered.

\subsection{The Relationship between Teachers ICT Efficiency and Their Satisfaction on CPD Online}

Studies show that there was a positive relationship between the level of ICT efficiency and the level of satisfaction on CPD online. The result of this study was in line with the findings of Sugunah (2014) who obtained similar findings. This indicates that the level of ICT skills will influence the level of CPD online satisfaction of teachers. Sharing knowledge among teachers not only enhances the professionalism of a teacher, but also develops the professionalism of all teachers in a school. Sukor et al. (2014). In addition, online training can enhance the knowledge and skills of teachers at any time. This is because teachers do not have the time to hold discussion sessions to share ideas to improve their teaching methods Awang et al. (2011). Therefore, the highly skills in ICT definitely give the teacher satisfaction as they can overcome the problems. In addition, Kler (2014) also stated that the use of ICT in knowledge management such as CPD can help a teacher reduce the information gap. This is in line with Aesaert et al. (2015) opinion that the lack of competency of teachers in the ICT will affect the development of their own knowledge. Therefore, teachers' ICT knowledge was a contributing factor to teachers satisfaction on online CPD. Schools and ministries should organize various ICT skills courses to ensure the online CPD can succeed and achieve their desired goals which were in line with Areej and Abdulrahman's (2011) study.

\subsection{The Differences in the ICT Efficiency between Genders}

This finding was contrast with the findings of Ahmad Hambali (2015) who found that there were no significant differences. In this study, male teachers had higher ICT skills compare to female teachers. This was in line with the findings of the study Nor Azan et al. (2000) which stated that men had higher ICT literacy than women. This is because the experience of using computers and computer purchases among men is higher than that of women. Moreover, most male teachers were pointed being ICT teachers and Frog VLE teachers in school. These opportunity enhance their computer experience because they need to constantly solve other teachers' computer problems in schools and indirectly increase their ICT skill among male teachers compared to female teachers. Therefore, female teachers should improve their computer experience in order to improve the level of proficiency on ICT.

\subsection{There Was No Significant Differences in the Levels of the Teacher's ICT Skills by Age}

Teachers of different ages have the same level of ICT skills. This contradicts 
Zainudin's (2008) study which stated that young teachers have better ICT skills, Sheiladevi and Rahman (2016) who stated that 'junior' lecturers are better in various ICT dimensions and Ahmad Hambali (2015) found that there are differences which is significant based on the age and experience of teaching a teacher. This is because today's educational administration is more concerned with the use of computers. Principals and senior assistant teachers need to use computers to complete routine administrative tasks. Not only that, all teachers without age should apply 21st century learning in the classroom. Many courses were also offered and conducted by all teachers. This indirectly enhances teachers' ICT skills to meet current needs.

\subsection{There Was No Significant Difference in CDP Online Satisfaction Level among Teachers}

Male and female teachers have the same level of CDP online satisfaction. This is in line with Goh's (2012) study which stated that gender does not influence the level of teacher satisfaction of the LDP. However, it contradicts John et al. (2005) state that job satisfaction varies by gender. This discrepancy arises due to the different working conditions in the United States and the older literature. Therefore, it can be said that all people regardless of gender will experience different training depending on their circumstances and environment. Gender is not a factor contributing to a teacher's training satisfaction. The satisfaction of the training experienced by the teachers depends largely on the training itself. Herzberg's two-factor theory (in Sondang, 2002) also explains that satisfaction comes from the Motivators factor, which is the responsibility and progress of the teacher himself. Therefore, the training conducted should focus on its own quality and be tailored to all male and female teachers.

\subsection{There Was No Significant Difference in CPD Online Satisfaction Level among Teacher}

Different age groups like novice teachers and experienced teachers have the same level of CPD online satisfaction. This contradicts Goh's (2012) study which found that teaching experience shows differences between teachers' satisfaction levels. This discrepancy may be due to the current situation. The KPM is now strongly emphasizing 21 st century learning and Online based learning. It was a huge change and involves all ages of teachers as it differs from the past. Teachers of different ages need the same training. Their level of satisfaction is the same if the training provided a quality and helpful to all teachers. Therefore, the training should be focused on what to do and not worry about teachers of different ages. It is supported by the study of Maria and Theodosia (2016) who stated that the training provided can change perceptions and improve teachers' knowledge and skills effectively.

\section{Conclusion}

Overall research has been able to identify the relationship between the level of 
ICT skills and the level of online LDP satisfaction of teachers at Bachang zone school, Malacca. Teacher GPA proficiency levels are at a high level, while LDP online teacher satisfaction levels are high. Gender factors of teachers have an influence on the level of ICT skills, but do not have an effect on LDP online teacher satisfaction. In addition, age factors had no effect on both levels of ICT skills and online LDP satisfaction. Because the ICT skills contribute to the online LDP satisfaction of teachers, they need to provide regular support and stimulate the internal motivation of teachers to ensure LDP online teacher satisfaction. However, this study involved only urban teachers from Bachang Zone, Malacca. Therefore, it is proposed that further studies be conducted in rural schools. This study can serve as a reference to the MOE, JPN, BTPN, PKG and schools on aspects that need to be improved in terms of TMK skills and online LDP satisfaction to ensure continued use of e-learning websites. Ongoing training in online services can enhance teacher performance and achievement and further develop our nation's education system as the technological age continues.

\section{Acknowledgements}

This research was partially supported by grant received from the Faculty of Education, Universiti Kebangsaan Malaysia code PP-FPEND-2019.

\section{Conflicts of Interest}

The authors declare no conflicts of interest regarding the publication of this paper.

\section{References}

Aesaert, K., Van Nijlen, D., Vanderlinde, R., Tondeur, J., Devlieger, I., \& van Braak, J. (2015). The Contribution of Pupil, Classroom and School Level Characteristics to Primary School Pupils 'ICT Competences: A Performance-Based Approach. Computers \& Education, 87, 55-69. https://doi.org/10.1016/j.compedu.2015.03.014

Ahmad Hambali, M. D. (2015). Level on Efficiency on ICT (TMK) Islamic Teachers MRSM: A Survey of MRSM Tun Ghafar Baba. http://www.academia.edu/6037190/

Areej, A. A., \& Abdulrahman A. M. (2011). Implementing a Virtual Learning Environment (VLE) in a Higher Education Institution: A Change Management Approach. Journal of Theoretical and Applied Information Technology, 31, 42-52.

Awang, M., Ismail, R., Flett, P., \& Curry, A. (2011). Knowledge Management in Malaysian School Education: Do the Smart Schools Do It Better? Quality Assurance in Education, 19, 263-282. https://doi.org/10.1108/09684881111158063

Azizi, Y., Shahrin, H., Jamaludin, R., Yusof, B., \& Abdul Rahim, H. (2006). Mastering Research in Education. Kuala Lumpur: PTS Professional Publishing Sdn. Bhd.

Goh, G. P. (2012). Knowledge Level and Level of Teacher Satisfaction in in-Service Training at Segamat District Secondary School. Doctoral Dissertation, Malaysia: University of Technology Malaysia.

Izani, I., \& Yahya, D. (2014). Servant Leadership and Its Influence on Change Management in Schools. Malaysian Journal of Education, 39, 19-26.

John, O. O., Michael Squillace, E. A. E. (2005). Gender Differences and Job Satisfaction: A 
Study of University Teachers in the United State. Women in Management Review, 20, 177-190. https://doi.org/10.1108/09649420510591852

Juan, E. J. A., \& Isabel O’Shanahan, B. (2016). Effects of Web-Based Training on Spanish Pre-Service and in-Service Teacher Knowledge and Implicit Beliefs on Learning to Read. Teaching and Teacher Education, 55, 175-187. https://doi.org/10.1016/j.tate.2016.01.006

Kler, S. (2014). ICT Integration in Teaching and Learning: Empowerment of Education with Technology. Issues and Ideas in Education, 2, 255-271.

Kokoc, M., Ozlu, A., Cimer, A., \& Karal, H. (2011). Teachers' Views on the Potential Use of Online in-Service Education and Training Activities. Turkish Online Journal of Distance Education, 12, 68-87.

Kuhlemeier, H., \& Hemker, B. (2007). The Impact of Computer Use at Home on Students' Internet Skill. Computers \& Education, 49, 460-480. https://doi.org/10.1016/j.compedu.2005.10.004

Luo, Y., \& Bu, J. (2015). How Valuable Is Information and Communication Technology? A Study of Emerging Economy Enterprises. Journal of World Business, 51, 200-211.

Maria, M. M., \& Theodosia, P. (2016). Pre-Service Teacher Training on Game-Enhanced Mathematics Teaching and Learning. Technology, Knowledge and Learning, 21, 379-399. https://doi.org/10.1007/s10758-016-9275-y

Ministry of Education Malaysia (2012). Malaysian Education Development Plan 2013-2025.

Mohd Jasmy, A. R., \& Mohd Yusoff, D. (2015). Information Technology Promotions and Markets: The 21st Century Capability. Bangi: Faculty of Education SMEs.

Mohd Jasmy, A. R., \& Norazani, M. Z. (2017). IT in 21st Century Education. Bangi: Faculty of Education SMEs.

Sharifah, N. P., \& Kamarul Azman, A. S. (2011). The Level of Readiness of ICT in Teaching and Its Impact on Preschool Students' Work and Behavior. Malaysian Journal of Education, 36, 25-34.

Sheiladevi, S., \& Rahman, A. (2016). An Investigation on the Impact of E-Learning Implementation on Change Management in Malaysian Private Higher Education Institutions. Pertanika Journal of Science \& Technology, 24, 517-530.

Sugunah (2014). The Relationship of Teacher ICT Skills and Knowledge Management in Primary Schools, Johor. Faculty of Education, Malasia: University of Technology Malasia.

https://www.researchgate.net/publication/283243731 ICT GURU DAN PRODUCTI ON IRECTORY DI SEKOLAH RENDAH_JOHOR

Zawiyah, M. Y., \& Zuhri, A. Z. (2014). Sharing Knowledge for Learning Purposes Using Social Media: A Model Need. Asia-Pacific Journal of Information Technology and Multimedia, 3, 47-61. 